\title{
How Adolescents with Asperger Syndrome (AS) Experience the Internet as a Communication Medium
}

\author{
By Mania Alehpour* \\ Bahareh Rajabi Behjat ${ }^{\dagger}$
}

This paper explores the use of the Internet by adolescents with Asperger in Tehran. Utilizing a grounded theory, the research is conceptualized from semi-structured interviews with 13 adolescent participants with Asperger, with ages ranged between 12-14 (younger adolescents) and 15-18 (older adolescents). The findings revealed that younger adolescents used the Internet for entertainment and looking up information but not for communication, while older adolescents used the Internet for communication purposes as well. As the adolescents got older, they simultaneously used the online and the offline environment for communication but because of lack of social skills for communicating with offline friends, they were more active on the virtual space and less active on the offline environment. As a result this lack of offline communication might increase their lack of social skills because they did not have enough contact in real life.

Keywords: Asperger, Autism, communication, Internet use

\section{Introduction}

The researchers have been studying the different groups of people and their use of the Internet. The Internet has affected many aspects of the world. Almost all groups of people use this technology for various purposes. Religious, ethnic and even mental minorities are active on the cyberspace and use it in different ways. However, mental minorities, like autistic people, are one of those groups whose activities in the cyberspace have been studied less than other groups. "Autism is a disorder characterized by deficits in communication and social interaction, a limited range of interests and repetitive stereotypical behaviour" (Coben \& Myers, 2008, p. 161). Autistic people fall along a spectrum of being, on one end, "high-functioning individuals of normal or superior intelligence, often described as having Asperger syndrome" (Benford \& Standen, 2009).

In this research, we studied adolescents in the Autism Spectrum Disorders (ASD) who were diagnosed as Asperger in DSM4, the research that says that they are people with Asperger syndrome.

\footnotetext{
* PhD Candidate in Communication Science, Department of Communication, University of Tehran, Iran.

${ }^{\dagger}$ Graduate Student in Educational Psychology, Department of Psychology, Alzahra University, Iran.
} 
"People with Asperger's Syndrome demonstrate deficits in both social interaction and in verbal and non-verbal communication. They have a narrowly circumscribed and rigid pattern of interests and routine. They are frequently physically clumsy. As children they have little or no interest or capacity for imaginative play. People with Asperger's Syndrome are described as egocentric and as lacking a basic capacity to understand and relate to others." (Walsh \& Mullen, 2004, p. 97). They are very verbal but they have problems with understanding nonverbal dimensions of social communication, aspects which adopt meaning, convey emotion and provide indications of status and role. Their social interactions may be incompatible, they have low empathy and are characterised by having trouble in tackling their own emotional responses (Barnard, Harvey, Potter, \& Prior, 2001).

Despite their problems in noitcaretni laicos, people with Asperger are gifted in various fields, but they may suffer from social isolation and psychological problems, such as low self-esteem, stress, anxiety and depression (Attwood, 2003). Adolescents with autism have often been reported to have problems in relationships with their peers and with involvement in social and recreational activities, and they spend lots of their free time involving in lonely activities and less time doing social activities (Orsmond \& Kuo, 2011) and they should be aided to be capable to live in this world without being marginalized.

Previous research has shown that communication through the Internet has helped people with AS to lessen the emotional, social and time pressures experienced in offline situations (Benford \& Standen, 2009), because they have difficulties in understanding the nonverbal communication and the Internet helps them overcome these problems. Based on previous researches and the capabilities of the Internet for communicating in nonverbal ways, we examined how adolescents with AS use the Internet and whether it helps them to not be isolated. In the other words if the AS adolescents are comfortable with the Internet for communicating with others, then we need to understand the reasons why and whether it is a positive or negative experience.

Adolescents are engaged in a struggle to create a stable and permanent sense of self to achieve a degree of self-awareness and self-acceptance (Hughes, 2014). Accordingly, we are concerned about how adolescents with AS experience the Internet at these ages. Thus, engaging in various forms of Internet use could have both positive and negative consequences. If we find an association between social and/or communication skills and Internet use, we might be able to use the Internet to positively impact these skills.

This article describes an exploratory survey among 13 Iranian adolescents with AS. They were in two groups, one between the ages of 12-15 and the other within the ages of 16-18. The survey was conducted in the autumn of 2014. At the time of data collection the subjects had access to the Internet by both personal computers at home and cell phones. This research studied the ways they used the Internet by both the cell phone and the PC as a technology.

The study presented broad contextual data about the expanse of, and the reasons for, Internet use by AS adolescents. It was followed by an interview study to explore in more depth the issues and questions appointed by the 
introductory study. The findings could be seen from a uses and gratifications perspective (Caplan, Perse, \& Gennaria, 2007) which posits that people use particular communication channels to satisfy their individual needs and motives.

\section{Literature Review}

There is very little empirical research into the use of the Internet by people with autism (Benford \& Standen, 2007). The majority of the researches have focused on the communicational capacities of the Internet and their main question is whether AS people use the Internet for communicating with their peers, families, friends etc.

Some researches on adults with Aspergers and high-functioning end of autism spectrum show that these people found the Internet as a way to communicate with other people rather than face to face communication. A study by Williams and co-operators (2010) reveals that many adults on the high-functioning end of the autism spectrum look up for better social connectedness and take benefit of interest-based online communities to foster successful, supportive relationships but they could not establish a friendship with online friends in the real world. These researchers explain how these people were not successful in establishing friendships with online friends in the real world. Actually computer mediated communication amplified problems of trust, disclosure, inflexible thinking and perspective-taking, making it difficult for some to maintain relationships.

Another research considered the Internet communication of 29 Asperger adult people in Japan. Watabe (2013) found that people with a diagnosis of AS tend to think that they could intercommunicate more correctly through the Internet than face-to-face communication because of lack of social skills. They used the Internet to a degree almost similar to controls, and tended to be friends to strange people, but also sometimes felt hurt when communicating on the Internet.

Benford and Standen (2009) investigate to find if the Internet is a comfortable medium for autistic people and whether this technology helps them improve their communication with others or not. The analysis, based on a grounded theory between 23 adult people with Asperger syndrome (AS), revealed how the subjects were able to use the Internet to reduce the emotional, social and time stressed experienced in offline conditions. They explain that aspects which contributed to the attainment of the Internet as a potentially more comfy communication medium consisted of visual anonymity, a disparate and more unrestricted pace of communication and the survival of text. Totally, the complexity of communication was depleted and a greater sense of control could be gained.

The findings in similar researches on adolescents with AS reveal that they do not use computers or cell phones to communicate with others. Durkin (2010) in his research described that adolescents with AS were less likely to 
have access to cell phones and, if they used them, they tended to use cell phones for non-communicative features, such as games rather than talking to peers. He pointed out that People with AS tend to have restricted skill to take part in correlative communication and weaker social motivation.

Kuo, Orsmond, Coster, \& Cohn (2013) explored how adolescents with autism spectrum disorder (ASD) use media, including the internet, generally. In their study, $98 \%$ of 91 adolescents used computers (almost $5 \mathrm{~h}$ /day) on any given day. They most often watched cartoons, played computer or video games that involved shooting, and visited websites that contained information on video games. Researchers found that Adolescents with ASD who visited social networking websites or received emails from friends reported more positive friendships than those who used computers for other points. Notably, peers were the companions with whom adolescents with ASD most frequently engaged in these computer activities.

\section{Method}

The study followed Strauss and Corbin's grounded theory methodology version, whereby the theory is derived from data (Scott, 2014). Its use facilitated an in depth analysis of adolescents with AS using the Internet by moving beyond "how" they use the Internet.

Participants were recruited through clinics or private school teachers working with adolescents with AS, and advertisements were posted on autismrelated Facebook pages. This research involves 13 adolescents (Table 1), identified with Asperger syndrome using strict DSM-4 criteria. Diagnoses were based on the complete information from clinical test, which contained interviews with parents and their children, and re-examining former psychiatric, psychometric and educational records. 10 persons of Participants were selected in clinics in Tehran and 3 of them were found through Facebook. We sent a message through Facebook and an email, in addition to talking with some of them and their parents in person, explained about our research then requested them to cooperate with us. After they accepted, they were confirmed by the clinics that they were the subjects. The participants' ages ranged from 12 to 18 and all of them were boys.

The autism diagnosis is relatively rare in girls; Asperger's is even rarer. Boys outnumber girls with autism by 4 to 1 in "high functioning autism", and Asperger's, the gender ratio is estimated to be 10 to 1 (Sarris, 2013). We could not find girls with Asperger who use the Internet. On the other hand we wanted to integrate our data. All of the participants were from the upper and middle classes and they had access to the Internet by cell phone and PC at home. 
Table 1. Participants

\begin{tabular}{|l|c|c|c|c|l|}
\hline Participants & Samples & Found on & \multicolumn{2}{|c|}{ Sex } & Notes \\
\cline { 3 - 5 } & & Facebook & Boy & Girl & \\
\hline $\begin{array}{l}\text { Adolescents } \\
\text { in the middle } \\
\text { schools }\end{array}$ & 7 & 3 & 7 & 0 & $\begin{array}{l}\text { Their ages were between 12-15 } \\
\text { (guidance school is after 5 years } \\
\text { elementary school) }\end{array}$ \\
\hline $\begin{array}{l}\text { Adolescents } \\
\text { in the high } \\
\text { schools }\end{array}$ & 6 & 0 & 6 & 0 & Their ages were between 16-18 \\
\hline
\end{tabular}

Note: $\quad$ Average age $=15$ years.

Standard Deviation $=1.92$

Source: Authors' estimations.

This study employed a purposeful sampling technique because we had to choose subjects who used the Internet. Sampling was driven by conceptual emergence and limited by theoretical saturation. Consistent with "theoretical sampling" (Breckenridge, 2009), participants were selected on the basis of how they informed and validated the emerging theory. We continued sampling until theoretical saturation happened and we made sure that there was no data to foster our categories.

\section{Semi-Structured Interviews}

A semi-structured interview schedule was developed. The initial schedule focused on participants explaining how they used the Internet. Following the data analysis, the schedule was modified and focused on the emerging theory. The audio-recorded interviews were conducted and they varied between 35 and 80 minutes.

\section{Recruitment and Ethical Considerations}

Eligible adolescents with AS and their parents received study information from us through Facebook, email and in person. Interested Asperger adolescents and their parents contacted us to arrange interviews, and a written consent was obtained from participants.

\section{Collecting Data}

Collecting data lasted 3 months. Data was gathered pertaining to participants' experiences, motivations and perceptions regarding the activities on the Internet. The interviews were conducted in person and were recorded on a digital Dictaphone, in accordance with the informed consent of participants, and transcribed. Being flexible enough in terms of the content, wording and arrangement of questions was important to allow the interviewee more freedom in how they told their story and allowing unanticipated categories to emerge. We used the help of an expert in the field of exceptional children to advise us about the ways to communicate with participants, and this allowed 
interviewees to be more comfortable in terms of the communicative style. Collecting data has been done in two steps. In step one, we tried to make friendly communication with the subjects in some sessions and when we were sure they were prepared to participate, we interviewed them.

\section{Data Analysis}

Interviews were transcribed and analysed consecutively, reflecting the continuing interaction among data collection and analysis. Line-by-line coding highlighted emergent concepts and transcripts were simultaneously analysed to facilitate analytical and interpretive triangulation. The procedure was iterative, containing continual comparison, development and purification of categories as data was collected. Possible connections among categories were explored, relating, for instance, to contexts and results. Axial coding (Strauss \& Corbin, 1998) was used to explore the relationships between categories, supplying a framework to explore the conditions related with beliefs and potential consequences. The theory was refined through "selective coding" where the categories emerged. There was relation amid emergent categories and the data collection process in terms of topics and questions was raised eventually within interviews, and several sampling for contrary cases for further elucidation of present categories. This very interactive analytic process continued until theoretical saturation had been attained, that was when categories were well developed and did not modify through new comparisons.

\section{The Emerging Categories}

The categories that emerged from the analysis were "Seeking Information", "Communication" and "Entertainment". All the ways of using the Internet that participants explained to us were in these three categories.

Because of the extended range of adolescent ages (12-18) we divided them into two groups and analysed their answers singly: younger adolescents (Table 2) and older adolescents (Table 3).

Table 2. Categories and Subcategories for Younger Adolescents (12-15)

\begin{tabular}{|l|l|}
\hline Categories & Subcategories \\
\hline Entertainment & Gaming \\
& Downloading \\
\hline Seeking information & Vehicles \\
& News \\
& Nature \\
& Weather \\
& Audio-visual products \\
\hline
\end{tabular}

Source: Authors' estimations. 
Table 3. Categories and Subcategories for Older Adolescents (16-18)

\begin{tabular}{|l|l|}
\hline Categories & Subcategories \\
\hline Entertainment & Gaming \\
& Downloading \\
\hline Seeking information & Vehicles \\
& Weather \\
& News \\
& Nature \\
& Audio-visual products \\
\hline Communication & Social networking \\
& Chatting with online friends \\
\hline
\end{tabular}

Source: Authors' estimations.

\section{Seeking Information}

Seeking information was one of the ways that both older and younger adolescents used the Internet. They searched for information about their favourite fields, like cars, music, weather, news etc. All cases, particularly the younger adolescents, visited websites about their interests, looked for information on their interests such as nature (animals, places, etc.) or cars.

"I like to look for cars for adoption, because I like cars" (Amirhossain, 12 years old).

"[I search for] Cars, Cars equipped with all sorts of things ... I just go online and type "cars image"" (Madiar, 13 years old).

They were interested in nature too. They liked to know about animals, places, the Earth etc.

"My father and I spend hours sitting on the computer and searching about animals and the places they live. We look for interesting spices and like to know which of them live in Iran." (Poyan 16 years old).

They were interested in searching about the weather too. Saman, 13, said:

"I always go to the Internet and search about the weather and then inform my teacher and classmates about that. They encourage me and like to know about weather!"

\section{Entertainment}

Both younger and older adolescents use the Internet for entertainment too. Downloading/listening to music, films, pictures, animations (audio-visual 
products) were other activities of the participants on the Internet. These kinds of activities were put under the entertainment category.

The Internet was a big source of entertainment for all adolescents in this research:

"One of my favourites is downloading music about the singers that I like. I have a big collection of my favourite songs that are categorised based on singers." (Poyan, 16 year old).

They enjoyed the Internet a lot for this because they could fill their own time without feeling lonely.

"I have few friends in the offline world. So I spend most of my free time on the Internet, surfing on it, downloading cartoons, film, music, game. I play games online too. It is enjoyable for me without having bad feelings of being alone." (Ali, 15 years old).

All of these activities were for passing free time and enjoying it, so we put all these under the "entertainment" category.

"After doing my homework my mom lets me use the Internet and have fun there. I immediately open the browser, search a game and start gaming online. Sometimes I asked my classmates about the new films and search them, and watch them online." (Ali, 14 years old).

"I spend my free time sitting on the computer and one of my main activities is downloading music, films, and games. I save them in my computer, categorise them, then use them in other free times." (Farbod, 18 years old).

\section{Communication}

The category that was different between older and younger adolescents was communication. Younger adolescents preferred to use applications like Viber $^{1}$, Skype and WhatsApp ${ }^{2}$ that are less interactive in comparison to other online social networks such as Facebook, Instagram, LinkedIn etc. They used these applications for communicating with one or two persons among their relatives or friends. Because of the rare use of communication capabilities by them, we did not assume a communication category for them. There were no differences between face to face communication and virtual communication for younger adolescents.

\footnotetext{
${ }^{1}$ Viber is an instant messaging and Voice over IP (VoIP) app for smart phones developed by Viber Medi.

${ }^{2}$ WhatsApp Messenger is an instant messaging app for smart phones that operates under a subscription business model. The proprietary, cross-platform app enables users of selected feature phones to use the Internet to communicate (Whatsapp's Website, 2015).
} 
Iman, aged 12, asserts: "There is no difference for me communicating with people face to face or online. I like both of them."

He explains about using the social networks application: "I don't have an account on Facebook and I don't know how to use it but I have the Viber application installed on my phone. I use it for messaging my aunt or my father."

Madiar, 13 year old, asserts: "I use Viber and Whatsapp that are installed on my mom's phone. She lets me message my teacher through them. I don't use Facebook. It is not interesting to me."

They communicated with a few relatives or friends.

Ali, aged 14, says: "I have a few friends... I don't see them or talk them a lot. I spend my free time alone or with my family... if I want to talk with my friends I choose the easiest way... maybe online or offline."

Older adolescents, in addition to using applications such as Viber and WhatsApp, used more interactive social networks websites like Facebook too. They used Facebook to share their ideas with strange people who were their online friends.

Figure 1. Categories for Two Groups

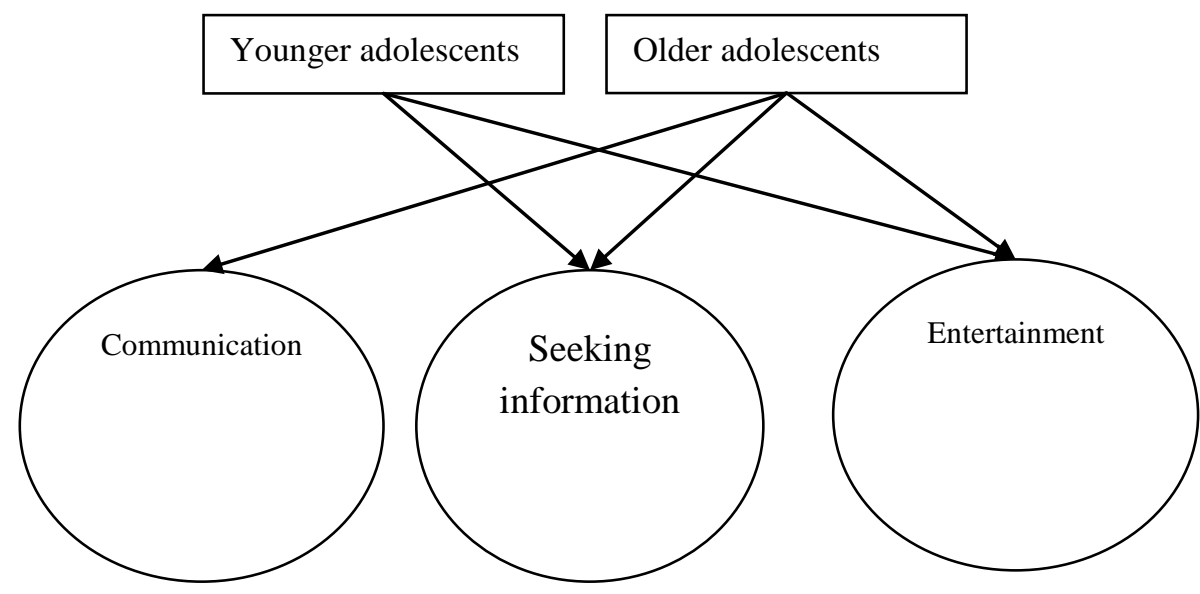

Source: Authors' estimations.

Farbod, aged 18, says: "When I was younger, Facebook was just an entertainment for me to know what it is, but as I got older, I felt that I need to use it for sharing my ideas and communicating with others. Beside it I use Whatsapp and Viber too for communicating with my friends." 
He continues: "I have a Weblog too for sharing my ideas with other people. My name's weblog is "an aspie boy". People read my posts and like them."

As the older adolescents needed to interact with the community and the real world, simultaneously, they started to use Internet social networks. But in the real world they could not interact as well as they did in cyberspace because they did not have the skills to communicate with others, which led them to being ostracised.

Reza, aged 18, asserts: "People in the real world don't like to communicate with me because I don't behave like them, but on Facebook and on my weblog I have a lot of people who read my posts and comment and are eager to meet me. But I can't establish a consistent friendship with them because they think I am unusual. They think I am rude and sometimes I think they defend me because they think I am arrogant ...."

Mehdi, aged 17, asserts: "After they meet me they are surprised that someone who wrote those awesome texts is actually me but after a while they are no longer interested in continuing the relationship with me."

Older adolescents had weblogs too. They shared posts on them and had a lot of audiences.

\section{Conclusions}

This study helps us understand how adolescents with AS use the Internet and why. The analysis provides not only a model of the relationship between using the Internet and autistic communication between adolescents, but a wider view of the effects that the Internet may have in the life of adolescents with AS.

We can illustrate the results based on the use and gratifications theory too. The participants used the Internet based on their needs. Younger adolescents, due to their age, did not notice the communication capabilities of the Internet. They were cared for by their family and did not need to be sociable and accepted into society. They have few friends and some of them had no friends at all. Unlike them, the older adolescents were enthusiastic about using the Internet for communicating. They enjoyed using applications like Facebook and Instagram for communicating and sharing their ideas with others. During the teenage years, adolescents become more aware of other people and their relationships with them. While most teenagers are concerned with popularity, grades and dates, teens with AS may become painfully aware that they are different from their peers. For some, this awareness may encourage them to learn new behaviours and try to improve their social skills (NINDS, 2014). As the adolescents got older they were eager to communicate with others. They 
started experiencing both offline and online environments. But as they became more interested in the virtual world, they became less interested in the real world because they were not understood or known by society. People in society did not like to be associated with them because they view autistic people as rude or something similar. This fact may aggravate the autistic behaviour of AS adolescents.

Subcultures in the virtual world are precisely "non-body communication", space-less and detached from race, nationality, geography and even sometimes cultures expose trans-religious orientation (Ameli, 2003). Accordingly, the AS older adolescents preferred to live in the virtual world, because that world is immaterial and they are able to hide their poor social skills, so they might become more autistic. This kind of research shows that the Internet makes AS adolescents in this research more isolated in the real world because they are not known by people. In other words when people do not know that AS people cannot behave as "normal" because of their disorder they are not patient with them and reject them.

6 out of 10,000 people in Iran are autistic (Samadi, as quoted by Rajabi, 2012). This assessment shows that endeavours for educating ASD people, to make them able to communicate and live independently, is necessary. But society also must be educated to behave more patiently with them to prevent ASD people from becoming more isolated and preferring to continue their life on the virtual space.

\section{Limitations}

Autism disorder has not been known in Iran for long, so adolescents diagnosed with this disorder have been few. Accordingly, we have difficulties in finding subjects. Each individual case contained trade-offs amongst approachability, trust, privacy, and negotiating pre-existing power relationships (such as parent-child or researcher-participant). As a conclusion, we treat these data points as the stories that participants express about their lives, and seek for the meanings that participants find in them, rather than treating them as raw, unprocessed data. We had to ask the questions in diverse ways to make sure that participants realised what we were asking. Given the nature of the research questions, findings and claims, we do not see any intrinsic reasons to discredit the findings.

Consideration must be given to the effect of the major investigator and project interviewer, who had a history in speech and language therapy; the interviews and the research data should be explained within this context. Moreover, an aimed approach to sampling was taken. The outlooks of this little group of research participants cannot be supposed to be illustrative of all people with Asperger. The sample was biased toward the Internet users, who commonly have better incomes and are more highly educated.

The drive for greater control on social communication was a key stimulant for the use of in-person interview. 


\section{Acknowledgment}

Our thanks to the parents of participants who associated with us and also thanks to Madar and Koodak Clinic, Aeene Mehrvarzi Autism School and Beh Ara institute; the Autism Center of Shahid Beheshti University. Also, Ms Samira Godarzi - the teacher of autistic children, for her co-operation.

\section{References}

Ameli Renani, S. R. (2003). New Culturology: Dual Globalization and Future Culture: An Articulation on Virtuality of Culture. International Conference on Information for All: Culture and Information Society. $1^{\text {st }}-5^{\text {th }}$ December, Moscow.

Attwood, T. (2003). Cognitive behaviour therapy. In L. H. Willey (Eds.), Asperger syndrome in adolescence: living with the ups, the downs and things in between. Philadelphia, PA: Jessica Kingsley Publishers.

Barnard, J., Harvey, V., Potter, D., \& Prior, A. (2001). Ignored or ineligible? The reality for adults with autistic spectrum disorders. London: National Autistic Society.

Benford, P., Standen, P. ( 2009). The Internet: a comfortable communication medium for people with Asperger syndrome (AS) and high functioning autism (HFA). Journal of Assistive Technologies, 3(2), 44-53.

Breckenridge. J. (2009). Demystifying Theoretical Sampling in Grounded Theory Research. Grounded Theory Review. Retrieved from http://goo.gl/1Rvonq.

Caplan, S. E., Perse, E. M., \& Gennaria, J. E. (2007). Computer-mediated technology and social interaction. In C. A. Lin \& D. J. Atkin (Eds.), Communication technology and social change: theory and implications (39-57). Mahwah, NJ: Lawrence and Earlbaum.

Coben, R. E., Myers, T. (2008). Connectivity Theory of Autism: Use of Connectivity Measures in Assessing and Treating Autistic Disorders. Journal of Neurotherapy, 12(2-3), 161-179.

Hughes, F. (2014). General Characteristics of the Adolescent. Retrieved from http://goo.gl/IyTJUV.

NINDS - Institute of Neurological Disorders and Stroke. (2014). Asperger Syndrome Fact Sheet. Retrieved from http://goo.gl/6c3Q.

Kuo, M., Orsmond, G., Coster, W.J., \& Cohn, E.S. ( 2013). Media use among adolescents with autism spectrum disorder. Autism Journal. Retrieved from http://goo.gl/mk1J0T.

Orsmond, G. I., Kuo, H. (2011). The daily lives of adolescents with an autism spectrum disorder: discretionary time use and activity partners. Autism Journal. Retrieved from http://goo.gl/D56yv7.

Rajabi Behjat, B. (2012). Design and Implementation of Art Therapy Program for Improvement of Social Interaction of Student with Autism (Unpublished Master Dissertation). Azahra University, Iran.

Sarris, M. (2013). Not Just for Boys: When Autism Spectrum Disorders Affect Girls. Interactive Autism Network. Retrieved from https://goo.gl/xwHQBX.

Scott, H. (2014). What is Grounded Theory? Retrieved from http://goo.gl/5jTk5i.

Strauss, A., \& Corbin, J. (1998). Basics of qualitative research: Techniques and procedures for developing grounded theory (2nd ed.). Thousand Oaks, CA: Sage. 
Watabe, T. S. K. (2013). The Internet communication of outpatients with Asperger's disorder or schizophrenia in Japan. Retrieved from http://goo.gl/afjqFC.

Walsh, B. J., Mullen, P. (2004). Forensic aspects of Asperger's Syndrome. The Journal of Forensic Psychiatry \& Psychology, 15(1), 96-107.

Whatsapp's Wbsite. (2015). Retrieved from https://goo.gl/zBPZ5n.

Williams, D., Burke, M., \& Kraut, R. (2010). Social Use of Computer-Mediated Communication by Adults on the Autism Spectrum. ACM CSCW 2010: Conference on Computer-Supported Cooperative Work (425-434). 
